\title{
MIMETICS FROM FRANCE TO CAMEROON: A NEW APPROACH TO STATE CONTROL THROUGH TAXATION AND STATISTICS
}

\author{
Jean-Guy Degos \\ IRGO Research Centre Bordeaux \\ University of Bordeaux (France) \\ Guy Djongoué \\ IRGO Research Centre Bordeaux \\ University of Douala (Cameroon)
}

\begin{abstract}
In all countries of the world, small business units form the core of the local economy, and key players in generating value added. In this paper, part of our work is devoted to a theory of State control over private entities and on the behavior of Cameroonian businessmen to constraints imposed by OHADA accounting system on the one hand. The work on the other hand also present some thoughts on how the business structures of these countries could evolve under the framework of a control theory, taking into account a situation that is evident in the nearest future - in the first place accounting and tax problems especially with small businesses and other entities that are currently being concealed and protected by the informal sector, which without doubts will stand to be lost in a new world that is not yet an African reality, where electronics, computer science and social networking sites are the order of the day, associated with great governments desires and pressure from the fact that it allows for government inquisition will inevitably lead to the disappearance of a large part of the informal sector.
\end{abstract}

Keywords: State control, Taxation, Small Business units, Statistic knowledge

JEL Code: H21, C42, M41

\section{Introduction}

The future has a long past for Africa in general and for Cameroon in particular. This long past weighs heavily on the continent the same way it was for colonial masters that colonized Africa several times in her history. Many African countries have seen their destiny modified not only during the era of colonization but also after this period. In all or almost all African countries' traditional, private, family, public and political structures witnessed the superposition of traditional institutions and structures that were adopted from mimetic (Girard, 1961, 1965), specifically in political aspects. This mimetic concerned the notion of the state and sovereignty under the debated monopoly of organized constraints - army and the military, police force and the police, representatives of upper and lower house of the parliament legislating and making the laws public. Old structures from which the informal sector is rooted - characteristics and forms have not yet completely disappeared. These old structures are obliged to intermingle with postcolonial structures imitated from the colonial masters who imposed and forced them in several domains. This informal sector that is very much a reality is viewed by new leaders in different countries who are very much versed with multinational companies as major stumbling blocks to modernity. But this blockage still has a great resistance capacity particularly as to what concerns tax and accounting and often ignore the fact that they are important in wealth or value creation. It is difficult and less desired with the present situation that can evolve in the long and medium term to implant in many African states a system that is comparable to that of Americans or Europeans. This particularly due to the fact that there exist a strong informal sector escaping from all statistical measures organized by the public and private organs, escaping as well from the imported banking 
circuit and from the exhaustiveness in the growth of transactions: they do not even know their departure point, their destination point, nor their real amounts and it is difficult to locate or map, measure and tax their activities. If the informal sector remains under this situation, statistical methods, fiscal and accounting standards will not attain transparent and an absolute economic control over African transactions.

\section{Methodology and Theoretical reference}

This work is an extension of several scientific studies previously published concerning university governance and the organization of accounting lessons (Degos, 2013), the control of French government on French accounting professional structures for a century (Degos, 2014), the evolution of the reedition of accounts by statutory auditors for the French government (Degos, Mairesse, 2014). In analyzing the evolution of all these institutions to organizational structures we use the same reading guide that we mobilize once again. Institutionalists and neo-institutionalists theories allow the study of organizations within the context of their environment and to explain their evolution. As earlier mentioned, (Degos, Mairesse, 2014), these theories have brought in novelty in the understanding of the role of business organizations as they went beyond the simple description of elementary phenomena. The socialist Max Weber was earlier interested on the processes that have been imposed onto the modern social live - an omnipresent bureaucracy and constraining institutions in several societies. He qualified these processes as "Iron cages" created by institutionalization. Institutionalists and neo-institutionalists theories seek to explain the homogeneity phenomenon in organizations and study the influence of institutional environment on these organizations. Thanks to Max Weber and his main disciples that have help to update his theory DiMaggio and Powell (1983), Roberts and Scapens (1985), Scott (1995), we are provided with a solid reflection base allowing the explanation of results obtained by comparing and projecting new cases such as those of Cameroon that we are going to compare with case in France.

\section{A theory of State control on economic activity in the long run}

If we take examples of French speaking countries, that have unwillingly been subjected to the influence of France for some decades now and which have later on decided by mimicry to look like France, we can describe in function of their structures necessary for a total control what is likely to happen in the long run, by studying the processes that have allowed the French state to have control that is almost total on the entire French economy. What are the different dimensions of state control? They were briefly mentioned (Degos, 2014). The first essential condition is to have a tight grip (strong hold) on all sorts of revenues, though this requires the possession of a statistical system facilitating the identification of these multiple revenue sources. The case of France showed that a general revenue taxation plan was easy to conceive than to apply as it took a century for an effective control. Jean Jaures proposed in 1894 the passing into law of a personal progressive income tax on revenue greater than 3000 francs per year (Neurisse, 1996). The 1917 law marked a step of no turning back as it touched all revenue categories: Estate revenue, mobile values revenue, industrial and commercial profits, agriculture profits, Salary, Wages and Pensions, credits and deposit revenue, revenue from non-commercial activities. With these principles suggested, it is important to choose between justice and efficacy: An effective or efficacious tax is always unjust and a just tax is rarely effective or efficacious. In France, arbitration was often made on households' family quotient and on the deductibility of charges for companies: on limiting family quotient and to disperse the several legitimate charges so as to allow for a reasonable increase in state revenue. The second dimension not to be neglected is the necessary relay of administration agents' actions with external competent and efficient experts. The Academic corporation of 
Accounting founded in 1881, created the first complete system of accounting lessons, with a bookkeeping certificate (1st degree created in 1990), an accounting diploma (2nd degree created in 1881) and a non-official license of chartered accountant (3rd degree, created in 1905), but the French people were not ready to totally adopt without reserve double entry accounting for both the private and the public. We equally observe in Cameroon context, similar behaviors where amongst the obstacles related to the mission of statutory auditors we can underline the incompetence of legal accounting professionals (Djongoue, 2008).

The ministry of public instructions addressed issues of chartered accountants in a text that was not all that perfect but was worth existing. At the beginning of the 2nd World war, in 1941, 3,000 French professionals pretended to be chartered accountants but only 250 of them had official chartered accountants license and 600 of them obtained the title by protection and not through official exams. During victorious occupation by France, the institution of the first accounting plan and the first National order of chartered accountants precipitated issues (Degos, 1998, p. 103-105). Within this context, the establishment of an accounting plan like that of the Soviet Union after the Russian revolution of 1917 allowed at the same time the monitoring of prices, quantities, performances and the putting into regulated plans French economy. In 1948, 1963, 1981 and 2010 several decrees came out modifying the chartered accountant diploma system, with 1,600 decrees at independence to 20,000 decrees presently and a special academic profile is put in place since 1969 for statutory auditors. The government became aware that well trained certified professionals that have taken vows were necessary to the economy and that their activity was centered on businesses lives and implicating the urgent intervention of the ministry of national education the successor of the ministry of public instructions beside the traditional ministries of finance and of Justice. The ministry has a strong grip on the training of accountants and this is closely monitored by general inspectors of National education and academic rectors.

But the deliverance of a diploma is not sufficient: the interface general law, commercial and fiscal law and the professional regulation need to be assured by closely monitoring accounting regulations, the structure of contractual audit and the rigor of legal or statutory audits. The National association of statutory auditors under the tutelage of the ministry of justice, put together all the individual statutory auditors and statutory auditors' companies registered on the list of each court of appeal. As for the National institute of public accountants, governmental commissions assure the interest of the state. In year 2000, the commercial code was completely rewritten, and the 648 old articles were replaced by 958 new articles placed under 9 books that are more homogenous than the previous books. With a regulation of the auditing profession and the revision of the commercial code, completed by a monetary and financial code, the state made much advancement in the control of accounting but the process was again accentuated due to the coincidental reasons from the Enron Andersen's Case.

The last dimension of state control over the economy lies at the level of the financial market and on the control of public and private book keeping. One of the consequences of the falling into bankruptcy of the American groups Enron, WorldCom and others was the reinforcement of the tutelage of the state over financial institutions and on statutory auditors, though this reinforcement did not later on prevent the financial subprime crisis of 2007-2008 whose consequences were later on felt on the entire international live. The law of 2nd August 2003 regrouped and reinforced control authorities of financial activities leading to the setting up of a Financial Market Authority as a result of the merging of the commission of stock exchange operations and the financial market council. This modernization is desired to be generalized to the organizational aspects, to control and to the exercise of statutory auditors' profession. Before the 2003 financial security law, the French accounting profession was used to the putting into tension of their activities by the Financial Market Authority which came to 
replace the financial market council and the stock exchange operation commission that created the high council of statutory auditors and revised the authorities of prudential control. Accounting Standard Authority ANC is responsible to elaborate public accounting norms and to harmonize them with private accounting norms. The different French governments as far back as 100 years were provided with the means of not only controlling more closely all the sectors of French economy - even with the unavoidable powerful effects of globalization- but also, they have always had a unique sense of maximum control. We can think that the future of Africa in general and that of Cameroon in particular follow this theoretical model, with the notable differences owed to the structural specificities of the continent: Demographic, technical and financial.

\section{The Current Cameroon Taxation and Accounting Situation}

In Cameroon just like elsewhere, the effects of an unavoidable past and the risk of an uncertain future exist. As to what concerns the past and the present, we are going to examine the country's fiscal and accounting structures. As for the future, we should always bear in mind the present, that the present population of Cameroon stands at 24 million inhabitants, with slightly less than 1500 births per day and that this population is projected at 52 millions inhabitants by 2050 (Source: Population du Monde) and at 82 million inhabitants for 2100 (source: madewulf@multitasked.net). Whatever the future events in the long run and medium term that concerns Cameroon, the executive power need not neglect these trends and deduce the effects from it now: it shall be impossible to maintain the present formal and informal structures.

A Specific fiscal reality seeking optimization. The present fiscal system of Cameroon partly looks similar to those of several European countries, but completed by relevant African specificities. Classically, corporate tax, personal Income tax are the main direct taxes and completed by indirect taxes such as value added tax (VAT). Other taxes and rates exist completing the Cameroon fiscal system, a great deal of legislative and regulatory texts are compiled in the Cameroon's tax code and fiscal laws. Tax payers can be categorized or subjected into three different tax systems:

The Global tax system is applied on individuals and moral persons with annual turnover tax exclusive less than 10 million francs CFA. They are subjected to the payment of global tax with the exception of forest exploiters or logging companies and persons of the liberal professions. Global tax is owed per council, per establishment and per activity where several different activities are carried out in the same establishment and per activity where several different activities are carried on in the same establishment. However, hawkers who show proof of payment of global tax in the council of the place of their residence shall not be taxable in other council arears for the same activity. Global tax is paid quarterly and within fifteen days of the end of each quarter for which it is due using and index card that carries information on the tax payer. The payment of global tax shall give entitlement to the issuance of a ticket signed by the taxation service. Failure to display the discharge tax ticket shall entail closure of the establishment.

The simplified Taxation System is for individuals and moral persons whose annual turnover tax exclusive range from 10 million to 50 million francs. Tax payers under this system are obliged to do bookkeeping for their businesses by respecting the Simplified accounting system (RS) of the OHADA accounting law or plan, but they can opt for the actual earnings taxation system under the same conditions. They are not authorized to charge or collect VAT on their sales and they are considered as final consumers as to what concerns VAT. 
The actual Earnings Taxation system is for liberal professionals and forest exploiters and for individuals or moral persons whose annual turnover tax exclusive is greater than or equal to 50 million Francs CFA. Tax payers here are obliged to do book keeping by respecting the real or standard system (SN) of the OHADA accounting plan. Only Tax payers in this category have the right to collect or charge VAT on their sales and deduct the VAT paid upfront on their operations.

The taxation system of Structural projects concerns large unit enterprises that fulfil the conditions of 28th July 2008 decree that specifies the modalities for the application of specific or particular tax system for structural projects in the Cameroon's general tax code. This system comprises non negligible tax advantages such as: the exoneration of tax payers from business license for 2 years following their constitution, the registration of deeds at a fixed fee of 50,000 FCFA: constitution or business incorporation deed, capital increase deeds and estate transfers or mutation deeds directly linked to the realization of the project, exoneration from VAT from the local purchase of construction materials and from importations made and meant for the realization of the project, the application of an accelerated or abnormally high depreciation rate for specific fixed assets acquired during the launching or installation phase and prolongation phase, the extension of the period for the carried forward of previous business deficits from 4 years to 5 years.

The taxable base for corporate tax is a fiscal result or balance calculated from the turnover of the entity, theoretically reduced by all the revenue expenses incurred by the business to obtain this turnover. Like in European countries, some revenue expenses are however not supposed to be deducted from the turnover according to the law and should be reinstated to the accountant's profit. Some revenue items are not taxable and should be deducted from the accountant's profit. Like in France, the taxable profit is obtained by the formula: taxable profit $=$ Accountant's profit + reinstatements of non-deductible revenues expenses - nontaxable revenues items. This taxable profit is taxed at a unique rate of $30 \%$.

VAT is indirect tax par excellence and settled at the public treasury by legal VAT subjects who are charged with its collection. All natural or moral persons including public law collectivities and organisms realizing operations taxable to VAT. The application domains of VAT include the following operations: production, the provision of services, distribution, importations, exportations, real estate works, game of chance and entertainment. The taxable base is mostly the total or final cost of the transaction (goods, service rendered, and exchanges). The VAT rate stands at $19.25 \%$ with $17.5 \%$ principal and $1.75 \%$ as additional council tax. Exports are taxable but according to the law, they are presently being taxed at a zero rate. VAT liability is at the point when goods are supplied or exchanged. For services, the payment of advancements, the holding of guarantee or caution and real estate works VAT liability is at the point of Cash receipts or during the debit registration of credits if the tax payer opted for this debit system. Lastly for production capitalized or owned VAT is owed at the point of the first usage of the item concerned.

Excise Duties (DA) is common in African countries and is calculated on the value of a consumer product (ad valorem) and collected when some specific products are supplied into the local market imported or manufactured locally such as: beer from malt, gaseous and mineral water, natural fruit juice, vermouths, other fermented drinks and wines (cider, pear), brandy, whiskies, rum, gin and spirit, cigar, cigarillo and cigarettes made of tobacco or tobacco substitutes, foie gras, caviar and its substitutes, smoked salmon, fine pearl and precious stones, precious metals, jewelries, sport or luxury cars of cylinder greater or equal to $2000 \mathrm{~cm}^{3}$. The excise duty point is the supply of the goods or entry of the goods and merchandises into Cameroon port space as to what concerns imports. A reduced rate of $12.5 \%$ 
is applied on sports and luxury cars and a common rate of $25 \%$ is applied on all other products. Excise duty tax payers respect the same payment obligations like subjects of VAT.

Cameroon has equally instituted a special tax for certain operations. Tax on petroleum product concerns the petroleum activity, petroleum sector tax comprises of the upfront petroleum tax and downstream petroleum tax. The special tax on petroleum products (TSPP) stands at 120 francs for a liter of super petrol and 65 francs for a liter of gas. The TSPP point is the supply of petroleum product by the National refinery company, the introduction of petroleum product on the national territory and the first usage of petroleum products when it has to do with owned production or self-supply. The public treasury shares the proceeds from this tax with the road's funds. The Mining tax concerns activities of the mining sector. Just like with the petroleum sector, the mining tax distinguishes upfront operations of mining and downstream operations of mining. The upfront mining tax applies on all activities that precede the exploitation of mineral products. The taxable subjects of this tax are holders of mining titles or certificates notably: holders of prospection authorization, of permits for the research of mineral products and quarry products. Fixed duties are owed for the institution, the renewal and the mutation of mining titles or certificates. We equally have mining royalties that is calculated in function of the area exploited and proportional duties. The taxable base is the area under exploitation specified on the concession deed. The proportional duty is calculated on the quantity of products extracted. The downstream mining tax applies on the proper exploitation and production of mineral products: mining products, quarry and water products. The main downstream mining operators are quarry exploiters, mining public works service providers, glasswork exploiters and water exploiters for industrial and commercial purposes with the exception of SNEC. The downstream mining activities are taxed on several forms: extraction tax for mining products, production tax for quarry products, royalties for the production of water at the source, sanitation tax on pollution water, ad valorem tax on the quantity exploited. The tax base for mining activities is made up of the value of products extracted and quantity exploited. Forestry tax applies on forests concessions and is calculated annually. It is calculated in accordance with the area of forest concession attributed with a rate per hectare decided upon during a call for tender, it comprises of a technical tender (weighted at $30 \%$ of the total) and a financial tender (weighted at $70 \%$ of the total). Cameroon's taxation was for a long time ago independent from accounting but for some decades now just like the French's taxation is taxing a great number of economic activities. It is interested with accounting perspectives and the possibility to control this accounting for the betterment of State revenue and the development of the nation.

\section{OHADA Accounting System taking into account small business Units finally}

Most countries in Africa are not only characterized by the existence of several small business units but equally by a strong informal sector which permit these units to evade constraining taxes and rigid regulations that we evoked above and which according to international experts is a blockage to development as informal businesses are not submitted to law or benefit from advantages like access to basic infrastructure and basic financing. African governments in general and the Cameroon's government in particular take measures to limit and check informal exchanges. The highly suggested measure is the passage from a non-structured economy to more structured economy and the simplification of the registration procedure to the different commerce registrars which is the initial necessary condition for the legal, economic, accounting and financial existence of an entity. The African accounting plans adopted by the former French colonies and other countries of the African continent: Burundi, Rwanda, Zaire take into account this problem and they have brought in a new wave from the European accounting techniques (Djossa Tchokote, 2009) and have not just copied only the French accounting system. With great remarkable advancements of the OCAM plan of the 
common African and Madagascar (today Mauritius) organization between 1966 and 1970 i.e. adapting with respect to the accounting needs of enterprises (Djongoue, 2006), other accounting plans like SYSCOA and OHADA have continued with the standardization of accounting norms in Africa in line with the state control over the economy earlier announced in this article. OHADA accounting plan has the advantage that it takes into consideration all types of enterprises and groups from the very small business units to the very large business units and seeks to assure the first harmonization with the fiscal rules. According to section 11 and 13 of the uniform text - OHADA (2000), entities be them of lucrative or non- lucrative goal, public or private are classified in function of turnover. The standard accounting system of OHADA is applied on enterprises with turn over greater than 100 million francs, which is about 152450 Euro; at the official exchange rate.

The financial statements that are specific to enterprises of the abridged system i.e. enterprises of modest sizes (according to section 27 of OHADA, 2002) are: the balance sheet, the income statement and the annexed statement. Book keeping here is that of engagements. The balance sheet here is a simplified balances sheet on which we only distinguish on the asset side: fixed assets, current assets, treasury assets and losses on exchange-assets. On the liability side: equity, long term financial debts, current liabilities, treasury liabilities and gain on exchange liabilities. The income statement though inspired from the standard system is simplified: revenue expenses and revenue or income items are presented without a distinction into operating, financial and off ordinary activities. In this system, we distinguish some intermediary results like value added, profit/loss from operating activities (EBITDA), profit/loss from ordinary activities and the net profit/loss. The annexed statement of the abridged system contain the assessment method and presentation method, fixed assets and depreciation table, the provisions table, the debt/credit table and other information that do not necessarily concern enterprises of modest sizes, like the maturity dates for debts and credits in foreign currencies, or gains on short term financial securities or income from long term financial securities; but the ventilation of turnover into within region, off region and that realized locally, as well as VAT invoiced on sales, VAT deductible and non-deductible are relevant.

The financial statements of the minimum treasury system (according to section 28 of OHADA, 2002) present a statement of cash receipts and revenue expenses which describes a simple book keeping of receipts - expenditures. "In this case, the treasury situation or statement of the enterprise is the total cash in coffers, in the bank and in the form of postal cheques. The trading period profit is gotten by taking the difference between the cash receipts and the expenditures and we have the following equality: Profit $=$ Cash receipts - revenues expenses" (Kamdem, 2004, p. 67-68). This system seems to be simple but it is very much complicated for a majority of business units in the informal sector that never cultivated the habit or grew with the minds of book keeping even in its simplest form as cash books or bank account book of cash receipts and expenditures.

\section{Taxation associated to Accounting, a vector for the modification of private sector behaviors and strategy for statistics by the public authority}

As noted by Djossa Tchokote (2009), the question of bookkeeping standardization is of particular importance to developing countries, as standardization authorities need to consider at the same time international norms as these countries need not live in isolation and satisfy the specific accounting information needs of users which is completely separated from the actors of developed economies: the tradition, the culture, economic and judicial behaviors. The analysis of the accounting and financial situation of countries in the developing countries is interesting as these countries have original accounting characteristics. There is no heritage 
except colonial heritage as to what concerns the accounting and financial representation of the economic activity, and as such we cannot transpose on to it models coming from a different economic and cultural framework that is completely different and rejected for comprehensible reasons such as the Anglo-American or European accounting and financial models. It is very difficult, without adequate traditions and cultural structural structures to put in place a pertinent and effective information system, to organize the accounting work, to elaborate the procedure manual and to ensure a supportive interface between the technics of wealth or value creation, information technics and taxation technics. The weak economic strength and the strong demographic growth of these countries particularly leads to the necessary existence of structures that are capable of synthesizing demographic data, tax, accounting and financial data of all the business units and which will allow information users to put in place coherent strategies. Almost all tax revenue comes from the formal sector. The taxation function or duty is therefore much important and vital than in developed countries (Djossa Tchokote, 2000).

These four points borrowed from Djossa Tchokote allows for the appreciation of the nature and amplitude of the future work pending for the structuration of developing countries' economy, and which is indispensable so that these economies seize from being dominated by developed economies with predatory tendencies. Small entities are mostly local enterprises that are more or less national businesses. They have always been neglected in economic theories where as their economic importance or weight is determinant.

The Appropriation of the OHADA accounting system laws in an optic of fiscal optimization. Accounting information can have a great influence on the individual decision making of small entrepreneurs as to what concerns the pertinence of financial statement and accounting publication or reporting, the usefulness of financial data and the manner to which they are integrated to accounting, the attitude to the different accounting techniques, the judgements or relative importance and their particular tax consequences and the effects of decisions on accounting choices, alternative or complementary. One of the key problems to resolve is: What type and what size of information is supposed to be gotten from accounting when one is an entrepreneur or manager of the business unit, and is this information compatible with that required by the public authorities. What level of transparency can a business unit's information attain that will not jeopardize her own interest and allow her at the same time to be responsible business unit? Must business units respect the legal classification that has the tendency of disassociating information types with respect to the different types of activities (trade, handicraft, service provision) or different types of organizational professions? We should distinguish two main final users: the very small business units realizing a turnover of less than 3o millions francs CFA and medium size business units with turnover ranging from 30 million to 100 million. The obligation of respecting fiscal constraints leads in this case to approximations that are less rational and less faithful to the accounting principles especially in the mounting of annual accounts and trading period financial statements.

A partial check on public authorities' weaknesses: the development of Statistics. The National statistics institute (INS) is the official statistic service in Cameroon. It succeeded the first statistical structure created in Cameroon in 1946 in Douala. It was transferred to Yaoundé in 1957. In 2001, this unit was officially transformed to INS which is autonomous and went operational in 2005. In its long run development vision perspectives Cameroon elaborated her first growth and poverty reduction strategy. The objective of this vision is to make Cameroon an emerging, modern and democratic country by 2040. The government in the course of implementing the growth and employment strategy paper (DSCE) and the different ministerial sector strategies has expressed the need of reliable and quality information for the follow up and the assessment of the different programs and dispositions. Cameroonian statisticians have 
well understood that a statistical data is the output of a process whose implantation implies the combination of a set of technological, human and material factors. For it to be this way, it needs to be established on codified bases that are generally accepted or admitted and as such standardized. This statistical standardization which today can only be realized at the international level aligns in several standardization domains with international accounting norms, of which the African system OHADA is just an intermediary step. In this context, concepts and definitions that are derived from these standards are used in the National Information Statistics system (SNIS) in Cameroon following their adaptation to local needs. It was due to the precision of data content to these adaptations that definition manual and usage concepts in official statistical publications recently published her 5th edition with financial support from the European Union. Cameroon authorities seem to have well understood the strategic importance of effective statistical structures serving as a support tool to general policy, fiscal policy, accounting and financial policy making.

\section{Conclusions}

To have an absolute control over an economy requires much work, and it is sometimes a task impossible to realize given that the external environment is giving way for liberty and not for strict control. It is therefore sometimes more realistic to do an indirect control through accounting structures both public and private. For a long time ago the French state from which most examples have been copied by Cameroon have not gotten the means to control taxation and accounting, as she was neither controlling the general taxation system nor the national statistics system. Progressively she gained rational control of taxation by basing on accounting and fiscal data production, with the help of trained professionals as they promoted professional institutions that are closely monitored by the administration placed under the tutelage of a government commissioner, and deprived to an extent citizens and business units from the right of imagining their book keeping. By so doing, the state as such insured the complete control of the accounting domain be it public or private, and she has succeeded in harmonizing and making common public and private constraining rules. She has affirmed her regaling powers in a way not too different from the cultures of Anglo-Saxon countries. The political structures of most African countries that are more regaling than Anglo-Saxon structures seem to be like the French model, than all other models. In France, change of government or political changes have never tampered with the initial systems; modifications have always taken the same direction and contributing each time supplements to administrative control by the state and supplements in limiting the liberty of professionals and business units. Is the evolution of this control process adaptable to Cameroon? We cannot certify this yet as Africa which is going to become the most populated continent on planet in the future has its own intrinsic history to be written, and she needs to consider the social changes, political changes and international changes that shall be manifested by changes in the commercial structures of companies, personal income and custom duties directly related to natural resources and manufactured products. With the present state of our analysis the theory that we outlined seems to be validated or tested on several points. It appeared useful for us to reflect on the relationship between the sovereignty of a state, her fiscal system, her statistical system with her accounting system and their present and future evolution in general that is not necessarily coherent but in all becoming more and more integrated and controlled. 


\section{References}

Degos J. G. (2013). Academic Governance and Accountancy: complexity emergence and garbage can model. International Journal of Critical Accounting, Volume 5, no. 1, 2013, pp. $1-15$.

Degos, J. G. (2014). Elements of theory on state control applied to accounting: The French case. International Journal of Critical Accounting, Vol. 6, No. 1, pp.1-23.

Degos, J. G., Mairesse M. P. (2014). Elements of theory on state control applied to accounting: The French case. International Journal of Critical Accounting, Vol. 6, No. 1, pp.1-23.

Djongoué G. (1994). Appréciations critiques du Plan comptable OCAM dans l'optique de la gestion et de l'analyse financière de l'entreprise. Thèse de Doctorat 3ème cycle en Sciences de gestion, Université de Yaoundé.

Djongoué G. (2006). Du Plan OCAM au Système comptable OHADA: quels changements ? Revue d'Economie et Gestion Appliquées, juillet - décembre 2006, n 5, pp. 104-140.

Djongoué G., Degos J. G. (2014). OHADA accounting system's constraints and behaviour of Cameroon small size enterprises: an exploratory study. African Journal of Accounting, Auditing and Finance (AJAAF), Volume 3, no. 4, pp. 263-286.

Djossa Tchokoté I. (2009). La diffusion du système comptable OHADA; conception des principes et déclinaison des pratiques. Thèse en sciences de gestion, université Montesquieu Bordeaux IV.

Kamdem D. (2004). Système comptable OHADA (SYSCO). Collection Ecologos, Editions Danoïa et Cameroon University Press.

Girard R. (1965). Deceit, desire and the novel: self and other in literacy structure. Baltimore, Maryland: Johns Hopkins University Press.

Girard R. (1961). Mensonge romantique et vérité romanesque. Paris: Grasset.

OHADA (2002). Treaty and Uniform Acts, Juriscope, Yaoundé.

OHADA (2000). Droit comptable et système comptable OHADA. Journal officiel de l'OHADA, 4e année, $\mathrm{n}^{\circ}$ 10, 20 novembre, Secrétariat permanent, Yaoundé, Cameroun.

Ordre des experts-comptables camerounais (2002), Le passage au système comptable OHADA. ONECCA Info, n ${ }^{\circ}$ 6, février, pp. 5-38.

Wallace O. (1993). "Development of accounting standards for developing and newly industrialized countries". Research in Third World Accounting, Vol. 2, pp. 201-224. 